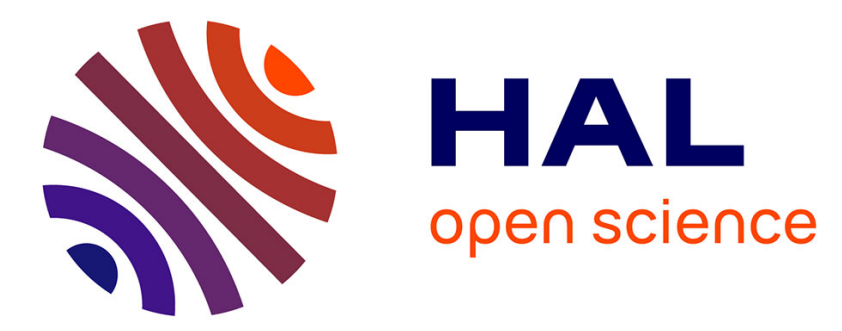

\title{
PRODUCTION OF METAL CLUSTER BEAMS BY USER VAPORIZATION
}

\author{
M. Pellarin, J. Vialle, J. Lermé, F. Valadier, B. Baguenard, J. Blanc, M. \\ Broyer
}

\section{> To cite this version:}

M. Pellarin, J. Vialle, J. Lermé, F. Valadier, B. Baguenard, et al.. PRODUCTION OF METAL CLUSTER BEAMS BY USER VAPORIZATION. Journal de Physique IV Proceedings, 1991, 01 (C7), pp.C7-725-C7-728. 10.1051/jp4:19917196 . jpa-00250876

\section{HAL Id: jpa-00250876 https://hal.science/jpa-00250876}

Submitted on 1 Jan 1991

HAL is a multi-disciplinary open access archive for the deposit and dissemination of scientific research documents, whether they are published or not. The documents may come from teaching and research institutions in France or abroad, or from public or private research centers.
L'archive ouverte pluridisciplinaire HAL, est destinée au dépôt et à la diffusion de documents scientifiques de niveau recherche, publiés ou non, émanant des établissements d'enseignement et de recherche français ou étrangers, des laboratoires publics ou privés. 


\title{
PRODUCTION OF METAL CLUSTER BEAMS BY LASER VAPORIZATION
}

\author{
M. PELLARIN, J.L. VIALLE, J. LERME, F. VALADIER, B. BAGUENARD, J. BLANC and \\ M. BROYER \\ Laboratoire de Spectrométrie Ionique et Moléculaire (U.R.A. $n^{\circ} 171$ ), Université Claude Bernard, \\ Lyon I, Campus de la Doua, Bât. 205, 43 boulevard du 11 novembre 1918, \\ F-69622 Villeurbanne cedex, France
}

\begin{abstract}
Using laser vaporization technique and standard Time-Of-Flight (TOF) spectrometric methods, Ionization Potentials (IP) of aluminum and iron clusters have been measured in extensive size ranges. These results are compared with recently published experimental works and analyzed in the self-consistent Spherical Jellium Background Model framework (SJBM).
\end{abstract}

1. - Introduction.

The metal cluster physics, subject of interdisciplinary interest, is currently an area of intense fundamental and technological research. Works devoted to isolated gas phase clusters have increased considerably since the introduction of the powerful laser-vaporization technique for producing supersonic metal cluster beams /1/. In this paper Al- and Fe-cluster size distribution spectra obtained from a recently operational pulsed laser vaporization source are presented. In order to test the performance of this apparatus the cluster IPs have been measured for comparison with other similar studies.

2. - Experimental (fig. 1).

A frequency doubled Nd:YAG (BMI), focused on the rod of the material of interest, produces a superheated and dense plasma. The laser-shots take place during the peak carrier gas flow (helium) generated by a synchronized pulsed gas valve, leading to partial neutralization and cluster growth inside the high pressure preexpansion zone. Subsequent free jet expansion quenches the nucleation and cools the metal clusters. Then the cluster expansion is skimmed (a few $\mathrm{cm}$ dowstream of the nozzle) to form a supersonic molecular beam, and the neutral clusters are photoionized by a frequency doubled dye laser pumped by an $\mathrm{XeCl}$ excimer laser (Lambda Physik, crystal BBO) during passage through the accelerating region of a TOF mass spectrometer. The mass separated cluster photoions are detected by an electron-multiplier and the TOF spectra are recorded in a microcomputer via a fast digital oscilloscope (Lecroy 9400).

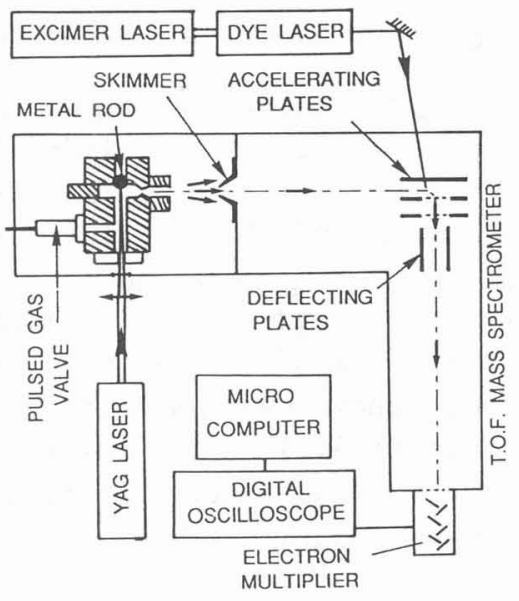

Fig. 1. - Schematic experimental set-up 


\section{3. - Results}

In order to increase the signal to noise ratio a few hundred TOF spectra are averaged (typically 500-1000) for each fixed parameter set (TOF transmission parameters and ionizing laser frequency), although the mass spectrum from one laser-shot often exhibits the qualitative pattern of the integrated curve. Then this TOF spectrum is normalized to the average ionizing laser fluence. During the experiments the dye laser intensity was kept low enough to avoid multiphoton processes. From these TOF spectra the cluster Photoionization Efficiency (PIE) curves are generated and the IPs deduced from the photoionization thresholds obtained by linear extrapolation of the PIE curves. Note that this current procedure rests on implicit assumptions : low internal excitation, favorable Franck-Condon factors, no significant competitive processes as predissociation or dissociative ionization. The precision of our extrapolated IP values is about $\pm 0.03 \mathrm{eV}$.

\section{Aluminum :}

Fig. 2a shows a typical TOF spectrum. The pronounced large-scale fluctuations in the overall pattern and the striking high abundances for particular sizes is the manifestation -via the IP size-evolution- of the electronic shell structure $/ 2 /$. The spectacular modification of the mass spectrum when the ionizing photon energy is decreased by a small amount (see fig. 2 b) rules out possible signature from the cluster abundance distribution in the incident supersonic beam (which is primarily governed by the nucleationdissociation dynamics).

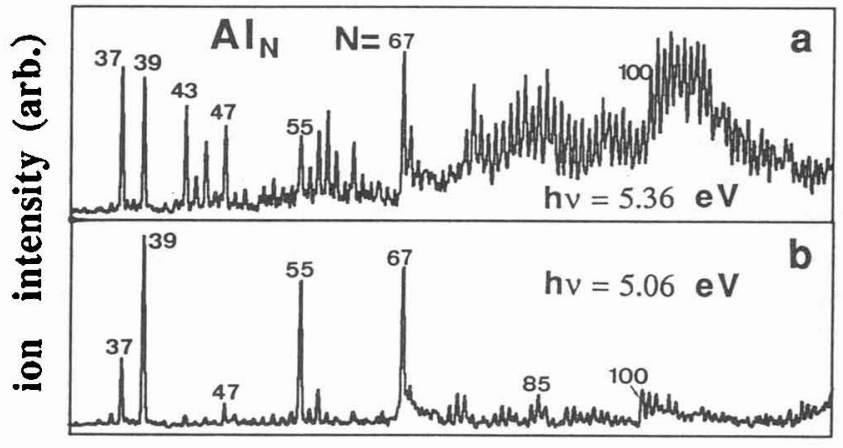

Fig. 2. - Aluminum cluster TOF spectra recorded with different ionizing photon energy

In the standard SJBM -worked out using the Kohn-Sham procedure in the Local Density Approximation formalism (LDA)- abrupt decreases in the IP curve occur after the filling-by the $n_{e}$ valence electrons $\left(n_{e}=\right.$ N.v where $\mathrm{v}$ is the atomic valence and $\mathrm{N}$ the cluster size)- of the $\mathrm{KS}$ ( $\mathrm{nl}$ ) shells. Along this filling sequence $3,4 /: 1 s^{2} 1 p^{6}\left|1 d^{10} 2 s^{2}\right| 1 f^{14}\left|2 p^{6}\right| 1 g^{18}\left|2 d^{10}\right| 1 h^{22} 3 s^{2}\left|2 f^{14} 1 i^{26} 3 p^{6}\right| 2 g^{18} 1 j^{30} 3 d^{10}$ $4 s^{2}$ । ...particularly strong discontinuities, indicated by vertical bars, are expected in the predicted IP curve. The corresponding $\mathrm{N}$-sizes (the so-called "magic numbers") reflect the filling of the highest levels of the KS level bunches $15,6 /$. Some of these magic numbers $\left(n_{e}=8,20,34,40,58,68,92,138,198\right.$, $254,338 \ldots)$ account very well for the strong dips observed at $N=47\left(n_{e}=138+3\right), 67(198+3)$ and $85(254+1)$ (see fig. 3a). In addition mass spectra recorded with higher ionizing laser fluence (enhancing multiphoton excitations) exhibit two high peaks $N=7\left(n_{e}=20+1\right)$ and $N=14(40+2)$, and a noticeable discontinuity at $N=23(68+1)$, three indications supporting the partial reliability of the SJBM to explain some features of the IP curve. However additional apparent shell openings at $\mathbf{N}=55,100$ (nonpredictable whatever the local reordering of the KS levels is) point out the limits of this oversimplified model. Moreover the shape-deformation or/and spin effects assumed to be responsible for the pronounced odd-even alternations in the $\mathrm{N}=55-62$ range and probably the large lowering of the $N=37,39$ IPs, cannot be accounted for in the LDA-SJBM framework. 

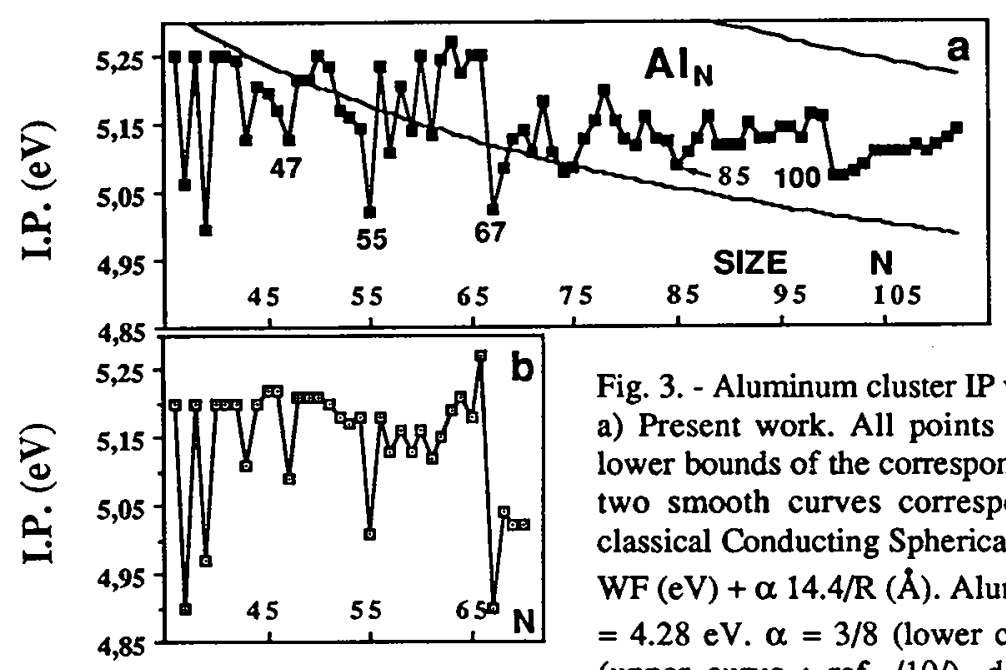

Fig. 3. - Aluminum cluster IP values.

a) Present work. All points at, or above $5.25 \mathrm{eV}$, are lower bounds of the corresponding cluster IP values. The two smooth curves correspond to the results of the classical Conducting Spherical Droplet model : IP $(\mathrm{eV})=$ $\mathrm{WF}(\mathrm{eV})+\alpha 14.4 / \mathrm{R}(\AA)$. Aluminum bulk Work Function $=4.28 \mathrm{eV} . \alpha=3 / 8$ (lower curve ; ref. $19 /$ ) or $\alpha=1 / 2$ (upper curve ; ref. $/ 10 /$ ), depending on the classical theoretical approach.

b) Results of Whetten et al. (réf. $/ 7 /$ )

Qualitatively our measurements are in excellent agreement with those of Whetten et al. $\Pi /$ (fig. 3b). Minor quantitative deviations are probably atuributable to differences in the procedure for the linear extrapolation of the PIE curves, or/and in internal cluster temperature.

\section{Iron}

In contrast with aluminum species the iron mass spectra do not exhibit any discontinuous large scale structures or isolated strong peaks. Indeed the smooth pattern of the envelopes reflects the slow sizeevolution of the IPs. The IP values, reported in fig. 4, are consistent with the results of Yang et al. /8/, although pronounced discrepancies are noted in the $\mathrm{N}=40-50$ range. The systematic shift of our photoionization thresholds has to be attributed to the low temperature of the liquid nitrogen-cooled source employed in ref $/ 8 /$.

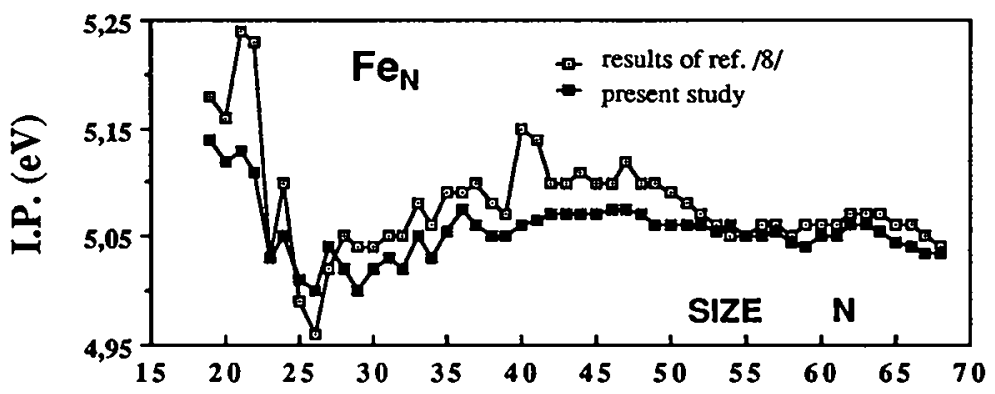

Fig. 4. - Iron cluster IP values. The results of the classical Conducting Spherical Droplet model are far above the experimental curves in this size range. $W F=4.50 \mathrm{eV}$ (bulk polycrystalline Work Function) 
Except a noticeable lowering of the IPs near $N=25$ this curve presents no characteristic sign relevant to some underlying shell structure. More striking is the large departure from the $1 / \mathrm{R}$-law of the classical Conducting Spherical Droplet model /9, 10/, which is expected to reproduce the rough trend of the IP curve in the large size range. The two strange features observed -the very slow IP decrease and the apparently shifted bulk work function value- have been attributed by Yang et al. to the size evolution of the Fermi level (accurate calculations have to be performed to prove this speculative hypothesis) and the choice of using polycrystalline bulk WF to represent IP $(\mathrm{N}=\infty)$ (the polymorphism of small iron clusters is supported by theoretical investigations and kinetic experiments). These large discrepancies indicate a slow merging of the iron microcluster properties towards the bulk ones.

\section{4. - Conclusion.}

These experiments emphasize the limits of the standard LDA-SJBM framework to describe non-alkaline metal clusters. Yet the clarity of the electronic shell picture offered by it (and its -partial- qualitative predictions too) makes this simple model irreplaceable for providing first analysis of the size effects for the cluster electronic properties. As a conclusion we list additional ingredients which are required to take into account the physical effects neglected in the standard SJBM (the first quoted can be easily implemented in the original model without breaking its specific characteristics) :

- Size effects : i) introduction of $\mathrm{N}$ - or/and $\mathrm{r}$-dependent jellium density, as suggested by Ekardt /4/ and justified by experimental observations of lattice shrinkage in microclusters. Recent calculations performed by Martin et al $/ 5 /$ demonstrate the sensitivity of the magic number sequence on slight departure from constant density ; ii) improvement of the exchange-correlation functional for the peripheral electronic cloud (the various local formulae are derived from the infinite uniform electron gas system).

- Shape effects : variational energy minimization against jellium deformations, for instance ellipsoidal distorsions as in the one-electron Nilsson-Clemenger model $/ 11 /$.

- Spin polarization : direct implementation by use of the L. Spin D.A.formalism. Importance of magnetic properties of small iron clusters has been proved in theoretical and experimental works.

- Atomic structure (the bulk density and the atomic valence are the only element-specific parameters in the SJBM) : use of pseudopotentials to accurately describe the ionic cores.

- Cluster structure : use of efficient optimization techniques, combining LSDA or usual quantum chemistry methods with molecular dynamics, to relax towards the ground-state structure (for instance the Car-Parrinello method /12/).

/1/ T.G. DIETZ, M.A. DUNCAN, D.E. POWERS, R.E. SMALLEY, J. Chem. Phys. 74 (1981) 6511.

12/ W.A. DE HEER, W.D. KNIGHT, M.Y. CHOU, M.L. COHEN in Solid State Physics (ed. by H. Ehrenreich, D. Turnbull, Acad. Press, N.Y. 1987), vol. 40, p. 93.

13/ D.E. BECK, Solid State Comm. 49 (1984) 381.

14/ W. EKARDT, Phys. Rev. B 29 (1984) 1558.

15/ H. GÖHLICH, T. LANGE, T. BERGMANN, T.P. MARTIN, Phys. Rev. Lett. 65 (1990) 748.

/6/ S. BJØRNHOLM, J. BORGGREEN, O. ECHT, K. HANSEN, J. PEDERSEN, H.D. RASMUSSEN, Phys. Rev. Lett. 65 (1990) 1627.

7/ K.E. SCHRIVER, J.L. PERSSON, E.C. HONEA, R.L. WHETTEN, Phys. Rev. Lett. 64 (1990) 2539.

/8/ S. YANG, M.B. KNICKELBEIN, J. Chem. Phys. 93 (1990) 1533.

19/ D.M. WOOD, Phys. Rev. Lett. 46 (1981) 749.

/10/ G. MAKOV, A. NITZAN, L.E. BRUS, J. Chem. Phys. 88 (1988) 5076.

/11/ K. CLEMENGER, Phys. Rev. B 32 (1985) 1359.

/12/ R. CAR, M. PARRINELLO, Phys. Rev. Lett. 55 (1985) 2471. 